\title{
Context Fear Learning in the Absence of the Hippocampus
}

\author{
Brian J. Wiltgen, ${ }^{1}$ Matthew J. Sanders, ${ }^{1}$ Stephan G. Anagnostaras, ${ }^{2}$ Jennifer R. Sage, ${ }^{2}$ and Michael S. Fanselow ${ }^{1}$ \\ ${ }^{1}$ Psychology and the Brain Research Institute, University of California, Los Angeles, Los Angeles, California 90095, and ${ }^{2}$ Psychology and Neurosciences \\ Program, University of California, San Diego, La Jolla, California 92093
}

Lesions of the rodent hippocampus invariably abolish context fear memories formed in the recent past but do not always prevent new learning. To better understand this discrepancy, we thoroughly examined the acquisition of context fear in rats with pretraining excitotoxic lesions of the dorsal hippocampus. In the first experiment, animals received a shock immediately after placement in the context or after variable delays. Immediate shock produced no context fear learning in lesioned rats or controls. In contrast, delayed shock produced robust context fear learning in both groups. The absence of fear with immediate shock occurs because animals need time to form a representation of the context before shock is presented. The fact that it occurs in both sham and lesioned rats suggests that they learn about the context in a similar manner. However, despite learning about the context in the delay condition, lesioned rats did not acquire as much fear as controls. The second experiment showed that this lesion-induced deficit could be overcome by increasing the number of conditioning trials. Lesioned animals learned normally after multiple shocks, regardless of freezing level or trial spacing. The last experiment showed that animals with complete hippocampus lesions could also learn about the context, although the same lesions produced devastating retrograde amnesia. These results demonstrate that alternative systems can acquire context fear but do so less efficiently than the hippocampus.

Key words: amnesia; memory; conditioning; emotion; rats; spatial

\section{Introduction}

The hippocampus is essential for the acquisition and retrieval of specific types of information. In rats, posttraining lesions of this structure severely impair recently but not remotely acquired context fear. These same lesions do not affect conditional fear acquired by discrete cues (Kim and Fanselow, 1992; Anagnostaras et al., 1999). Humans with hippocampus damage also show selective memory impairments. Recently acquired declarative memories cannot be recalled, although nondeclarative information remains intact. These similarities suggest that context fear conditioning may be a useful model of hippocampus function and declarative memory formation in humans (Squire, 1992; Fanselow, 2000; Rudy et al., 2002).

Although the human and animal literatures are mostly consistent, some differences exist. For example, lesions of the rodent hippocampus do not produce reliable anterograde amnesia for context fear (Maren et al., 1997; Frankland et al., 1998; Cho et al., 1999). Amnesia can be induced, however, with drug infusions or genetic manipulations that target the hippocampus. Antagonists of NMDA and acetylcholine receptors or blockers of protein synthesis severely impair the acquisition of context fear (Gale et al., 2001; Sanders and Fanselow, 2003; Matus-Amat et al., 2004). Deficits have also been observed in mice with mutations re-

Received Feb. 25, 2005; revised April 7, 2006; accepted April 8, 2006.

This work was supported by National Institute of Mental Health Grant MH62122 (M.S.F.), a National Alliance for Research on Schizophrenia and Depression Young Investigator award (S.G.A.), and a University of California, Los Angeles Research Mentorship Fellowship (B.J.W.).

Correspondence should be addressed to Michael S. Fanselow, Psychology Department, University of California, Los Angeles, 1285 Franz Hall, Box 95163, Los Angeles, CA 90095-1563. E-mail: fanselow@psych.ucla.edu. D0I:10.1523/JNEUROSCI.2685-05.2006

Copyright $\odot 2006$ Society for Neuroscience $\quad 0270-6474 / 06 / 265484-08 \$ 15.00 / 0$ stricted to the hippocampus (Rampon et al., 2000). These data suggest that the hippocampus is normally involved in context conditioning but is not necessary for learning to occur.

The standard explanation for the absence of pretraining lesion effects is that alternative systems compensate when the hippocampus is damaged. By acquiring context fear, these systems prevent the occurrence of anterograde amnesia. However, unlike the spatial maps acquired by the hippocampus, compensatory systems are thought to learn about simple, elemental cues (Maren et al., 1997; Frankland et al., 1998; Gerlai, 1998; Fanselow, 2000; Anagnostaras et al., 2001; Matus-Amat et al., 2004). The idea that lesioned animals use an elemental learning strategy is widely accepted, although it has never been directly tested. Therefore, our first experiment examined the way in which animals with hippocampus lesions learn about the context.

Previous experiments have shown that little to no learning occurs when shock is presented immediately after animals are placed in the context. This is known as the immediate shock deficit. Increasing the amount of context exposure before shock alleviates this deficit (Fanselow, 1986, 1990; Wiltgen et al., 2001; Frankland et al., 2004). This occurs because a minimum amount of processing time is necessary to form a representation or map of the environment (Fanselow, 1986; Wilson and McNaughton, 1993; Frank et al., 2004). In contrast, increasing the amount of exposure to discrete elemental cues tends to reduce the amount of conditioning (Kamin, 1965; Lubow, 1973). Consequently, this dissociation provides a way to test the content of learning in animals with hippocampus lesions. If they learn about the context, then increasing the amount of exposure before shock should enhance conditioning. If they learn about elemental cues, then 
conditioning should deteriorate as the amount of exposure is increased. The first experiment tested this idea.

Studies of spatial memory have shown that the hippocampus is particularly important for single-trial learning (Steele and Morris, 1999; Nakazawa et al., 2003). Consistent with this finding, hippocampus damage often slows the rate of learning but does not prevent animals from acquiring new spatial information across trials (Hannesson and Skelton, 1998; de Hoz et al., 2005). In our second experiment, we determined whether this was also true for context fear conditioning by varying the number of conditioning trials. We equated performance in this experiment by controlling the amount of space between trials. In our last experiment, we examined context fear learning in rats with complete lesions of the hippocampus.

\section{Materials and Methods \\ Subjects}

The subjects were 370 adult male (experiments 1 and 2) and female (experiment 3) Long-Evans rats (300-350 g) purchased from Harlan (Indianapolis, IN). The rats were maintained on a $12 \mathrm{~h}$ light/dark cycle (lights on 7:00 A.M.) in the Herbert L. Washington Vivarium in the Psychology Department at University of California, Los Angeles (Los Angeles, CA). Animals were individually housed 1 week before surgery and handled daily. All rats had access to food and tap water ad libitum. All procedures were performed during the light phase of the cycle.

\section{Surgery}

Dorsal hippocampus lesions. Male rats were randomly assigned to receive a lesion of the hippocampus or sham surgery. Animals were anesthetized with sodium pentobarbital $(65 \mathrm{mg} / \mathrm{kg})$ and mounted in a stereotaxic apparatus (David Kopf Instruments, Tujunga, CA). The scalp of each animal was incised and retracted, and the skull was adjusted to place bregma and lambda in the same horizontal plane. Small burr holes were drilled at the appropriate injection sites. A $10 \mu \mathrm{l}$ Hamilton syringe was mounted in an infusion pump (Harvard Apparatus, South Natick, MA) and connected to the injection cannula (28 gauge; Small Parts, Miami Lakes, FL) with polyethylene tubing (Fisher Scientific, Springfield, NJ). Lesions were made in the first two experiments by infusing NMDA $(0.4$ $\mu \mathrm{l} ; 20 \mathrm{mg} / \mathrm{ml}$; Sigma, St. Louis, MO) dissolved in $100 \mathrm{~mm}$ PBS, pH 7.4 (Sigma) at each site over a 4 min period. The drug was allowed to diffuse for $2 \mathrm{~min}$ after each infusion. Infusions were made at four sites (two anterior and two posterior). The two anterior dorsal hippocampus (DH) infusions were made at the following coordinates: $2.8 \mathrm{~mm}$ posterior to bregma, $\pm 1.6 \mathrm{~mm}$ lateral to bregma, and $4.3 \mathrm{~mm}$ ventral from skull surface. The two posterior DH infusions were made at the following coordinates: $4.2 \mathrm{~mm}$ posterior to bregma, $\pm 2.6 \mathrm{~mm}$ lateral to bregma, and $4.0 \mathrm{~mm}$ ventral from skull surface. Sham surgery involved similar treatment without cannula placement or drug infusion.

Complete hippocampus lesions. Complete lesions were made in female rats by infusing ibotenic acid $(0.1 \mu \mathrm{l} ; 10 \mathrm{mg} / \mathrm{ml} ; 0.1 \mu \mathrm{l} / \mathrm{min}$; Sigma) into 12 bilateral sites. The coordinates were $-2.1,-3.0,-3.0,-3.9,-3.9$, $-4.6,-4.6,-4.6,-5.3,-5.3,-5.3,-5.3 \mathrm{~mm}$ posterior to bregma, $\pm 1.0, \pm 3.0, \pm 1.4, \pm 3.7, \pm 2.6, \pm 4.6, \pm 4.1, \pm 4.1, \pm 4.3, \pm 5.1, \pm 5.1$, $\pm 5.1 \mathrm{~mm}$ lateral to bregma, and $-3.0,-2.7,-2.9,-2.7,-2.8,-6.5$, $-7.2,-3.5,-3.9,-6.1,-5.3,-4.5 \mathrm{~mm}$ ventral from the skull surface. The drug was allowed to diffuse for $1 \mathrm{~min}$ after each infusion.

\section{Apparatus}

Training and testing were performed in four identical observation chambers $(28 \times 21 \times 22 \mathrm{~cm}$; Lafayette Instruments, North Lafayette, IN). A video camera was positioned in front of the chambers to allow the subjects' behavior to be observed and recorded by an experimenter in an adjacent room. The floor of each chamber consisted of 18 stainless steel rods (4 mm diameter) spaced $1.5 \mathrm{~cm}$ apart (center-to-center). The rods were wired to a shock generator and scrambler (Med Associates, St. Albans, VT) for the delivery of footshock. The chambers were cleaned with a $5 \%$ ammonium hydroxide solution, and pans containing a thin film of the same solution were placed underneath the grid floors. Background noise ( $60 \mathrm{~dB}$, A-scale) was supplied by a fan positioned underneath the video camera.

\section{Procedure}

In experiment 1 , sham and $\mathrm{DH}$-lesioned rats were randomly assigned to one of five groups. Each group received a single shock after one of the following placement-to-shock intervals (PSIs): 12, 24, 48, 192, or $340 \mathrm{~s}$. The sample sizes for the sham groups were $12 \mathrm{~s}(n=18), 24 \mathrm{~s}(n=17)$, $48 \mathrm{~s}(n=26), 192 \mathrm{~s}(n=20)$, and $340 \mathrm{~s}(n=17)$. The sample sizes for the lesion groups were $12 \mathrm{~s}(n=18), 24 \mathrm{~s}(n=18), 48 \mathrm{~s}(n=26), 192 \mathrm{~s}(n=$ $18)$, and $340 \mathrm{~s}(n=17)$. On the conditioning day, rats were transferred from the vivarium into the experimental room. The rats were then were placed into the conditioning chambers in groups of four. Footshock (1.5 $\mathrm{mA}, 2 \mathrm{~s}$ ) was delivered simultaneously to all rats after the specified placement-to-shock interval had elapsed. Thirty seconds after shock presentation, the rats were removed from the conditioning chambers and returned to their home cages. Twenty-four hours after the conditioning session, the rats were returned to the context for an 8 min test. Freezing behavior, a defensive posture defined as the absence of motion except that necessitated by breathing, was assessed during the test using a timesampling procedure. Each rat was scored for freezing every $8 \mathrm{~s}$, yielding a total of 64 observations for each subject during the context test. All scores were transformed into a percentage freezing score by dividing the number of freezing observations by the total number of observations made during the test and multiplying by 100 .

In experiment 2 , sham and $\mathrm{DH}$-lesioned rats were randomly assigned to one of four groups. Two groups were trained with a single conditioning shock delivered at 48 or $340 \mathrm{~s}$ after placement into the context. The sham group sample sizes were $48 \mathrm{~s}(n=20)$ and $340 \mathrm{~s}(n=17)$. The lesion group sample sizes were $48 \mathrm{~s}(n=20)$ and $340 \mathrm{~s}(n=17)$. The other two groups were trained with three conditioning shocks equally spaced throughout a 48 or $340 \mathrm{~s}$ training session. The sham group sample sizes were $48 \mathrm{~s}(n=17)$ and $340 \mathrm{~s}(n=17)$. The lesion group sample sizes were $48 \mathrm{~s}(n=17)$ and $340 \mathrm{~s}(n=16)$. Other than these differences, training and testing were identical to experiment 1 . Shock reactivity was also scored during the $2 \mathrm{~s}$ shock and an equivalent baseline period (Godsil et al., 1997).

In experiment 3 , intact animals were trained with 10 conditioning trials ( 2 min placement-to-shock interval, $1 \mathrm{~mA}, 2 \mathrm{~s}$ shock, 1 min between shocks). Complete lesions of the hippocampus $(n=11)$ or sham surgeries $(n=23)$ were performed the following day. After recovery ( 14 d), the animals received an 8 min context test. The next day, the same animals were trained with five conditioning trials ( 2 min placement-toshock interval, $1 \mathrm{~mA}, 2 \mathrm{~s}$ shock 1 min between shocks). Fourteen days later, they received an 8 min context test.

\section{Histology}

Histological verification of the lesion locations was performed at the end of behavioral testing. Rats were perfused transcardially with $0.9 \%$ saline, followed by $10 \%$ formalin. After extraction from the skull, the brains were postfixed in $10 \%$ formalin/30\% sucrose until sectioning. Coronal sections $(50 \mu \mathrm{m}$ thick, taken every $150 \mu \mathrm{m})$ were cut on a cryostat $\left(-16^{\circ} \mathrm{C}\right)$ and mounted on glass microscope slides. After drying, the sections were stained with $0.25 \%$ thionin to identify neuronal cell bodies. Lesions were verified by visual inspection of the stained sections reconstructed on the rat brain atlas (Paxinos and Watson, 1998). After complete hippocampus lesions, the coronal sections of each brain were digitized. Nearly identical planes were identified between lesion and comparable sham rats, and then five to seven traces of total cortical area were made in NIH Image. Animals that had any remaining ventral hippocampus tissue or $>35 \%$ loss of total cortical area were excluded from data analyses.

\section{Data analysis}

For the context test period, the freezing scores were transformed into a percentage freezing score, as described above. These scores were then analyzed using an ANOVA. Post hoc tests were performed using Fisher's PLSD test. Statistically significant differences are reported when $p<0.05$. All data are represented as means \pm SEM. 


\section{Results}

Excitotoxic lesions damage the dorsal hippocampus

A photomicrograph of a representative DH lesion is shown in Figure 1. Similar to previous reports from our laboratory (Maren et al., 1997; Quinn et al., 2002), NMDA infusions caused complete bilateral destruction of the $\mathrm{DH}$, including neurons in the dentate gyrus, CA3, and CA1. Damage was restricted to the dorsal two-thirds of the hippocampus. Extrahippocampal damage was observed in some animals but was confined to overlying neocortical areas. A previous study from our laboratory showed that damage to these regions does not impair fear conditioning (Kim and Fanselow, 1992).

\section{Lesioned animals benefit from context exposure but remain impaired after a single trial}

During training, sham and DH-lesioned animals received shock after a specified amount of time in the context. Figure $2 \mathrm{~A}$ shows freezing levels during the context test for animals trained with an immediate shock (12 s) and those trained with a delayed shock (340 s). Immediate shock produced little or no context fear in sham and lesioned animals $(F<1)$. In contrast, when shock was delayed, the amount of fear increased substantially in both shams $\left(F_{(1,33)}=330.93 ; p<0.05\right)$ and animals with DH lesions $\left(F_{(1,33)}=\right.$ 38.47; $p<0.05)$. Previous studies have argued that this behavioral result reflects the time needed to form a spatial or contextual representation of the environment (Fanselow, 1986, 1990; Frankland et al., 2004). The fact that rats with $\mathrm{DH}$ lesions show this effect suggests that they also learn about the context.

Figure $2 B$ shows freezing levels during the context test for sham and $\mathrm{DH}$-lesioned animals trained at five different PSIs. Both sham $\left(F_{(4,93)}=31.2 ; p<0.05\right)$ and lesioned $\left(F_{(4,92)}=16.2\right.$; $p<0.05)$ animals exhibited systematic increases in freezing as the PSI was extended. This result clearly demonstrates that lesioned animals do not exhibit reduced freezing at longer exposure intervals as would be expected if they learned about a discrete elemental cue (Kamin, 1965; Lubow, 1973; Mackintosh, 1983). However, rats with DH lesions did freeze significantly less than sham animals $\left(F_{(1,185)}=16.15 ; p<0.05\right)$, and this impairment did not vary with the PSI $\left(F_{(4,185)}=2.29 ; p>0.05\right)$. Together, these results suggest that the $\mathrm{DH}$ is not required to learn about the context, although the amount of conditioning is reduced when it is removed.

Previous reports have shown that multiple-trial context conditioning is not affected by pretraining DH lesions (Maren et al., 1997). Therefore, trial number may be the critical factor controlling anterograde amnesia for context fear after hippocampus lesions. We examined this idea in our second experiment. To control the level of context fear across groups, we manipulated both the amount of context exposure and the number of conditioning trials.

\section{Multiple-trial learning is normal in animals with hippocampus lesions}

Context fear for sham and DH-lesioned animals trained with one shock (48 or $340 \mathrm{~s}$ of context exposure) is illustrated on the left side of Figure 3. The data from rats receiving three shocks (48 or 340 s of context exposure) are shown on the right side of Figure 3. As expected, freezing was enhanced by increasing the amount of context exposure $\left(F_{(1,133)}=27.37 ; p<0.05\right)$ or the number of shocks $\left(F_{(1,133)}=13.71 ; p<0.05\right)$. Similar to experiment 1 , rats with $\mathrm{DH}$ lesions showed significantly less context fear after a single shock $\left(F_{(1,72)}=10.51 ; p<0.05\right)$ delivered at $48 \mathrm{~s}$ or $340 \mathrm{~s}$
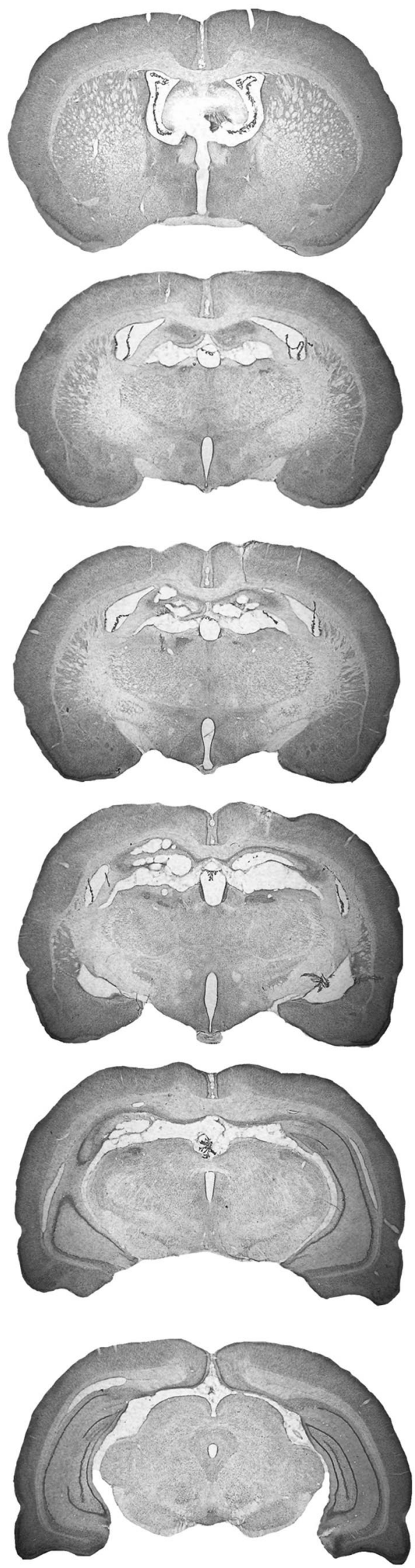

Figure 1. Photomicrographs showing thionin-stained coronal brain sections after excitotoxic lesions of the dorsal hippocampus. From top to bottom, the sections are $-0.80,-1.60$, $-2.60,-3.60,-4.60$, and $-6.0 \mathrm{~mm}$ posterior to bregma. 

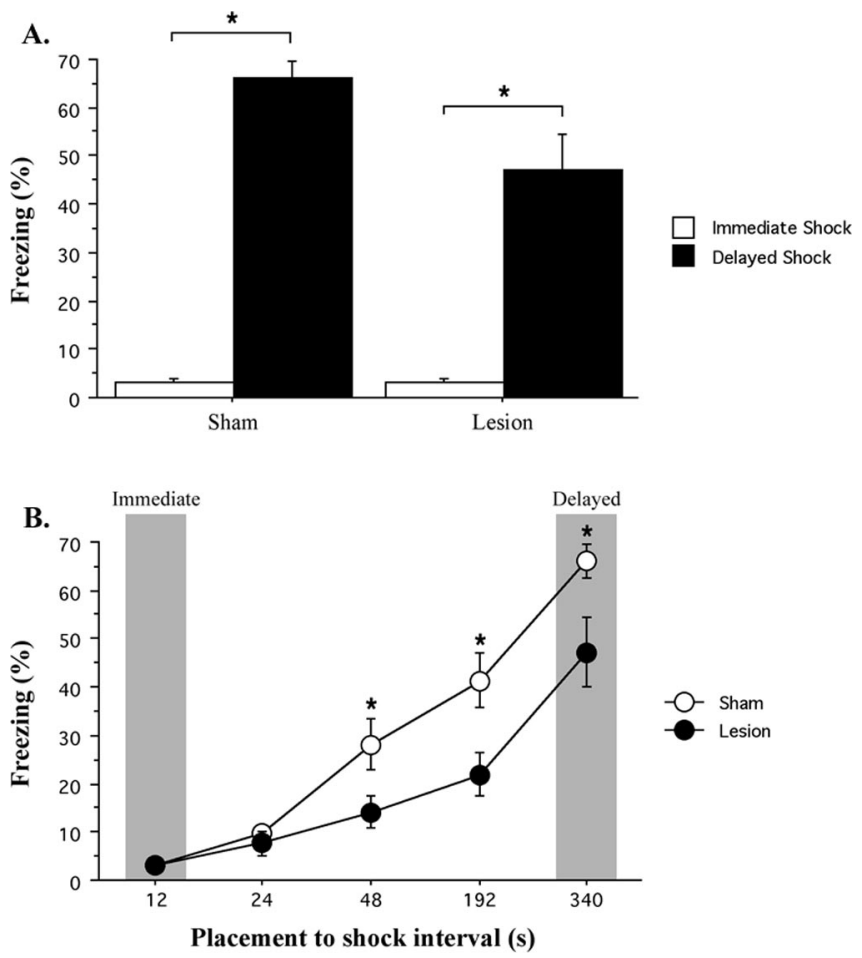

Figure 2. Mean \pm SEM percentage freezing during the context test for sham and DHlesioned animals. $\boldsymbol{A}$, Freezing levels for animals that received an immediate or delayed shock. $\boldsymbol{B}$, Freezing levels for animals that received shock $12,24,48,192$, or 340 s after placement in the context during training. ${ }^{*} p<0.05$, significant group difference.

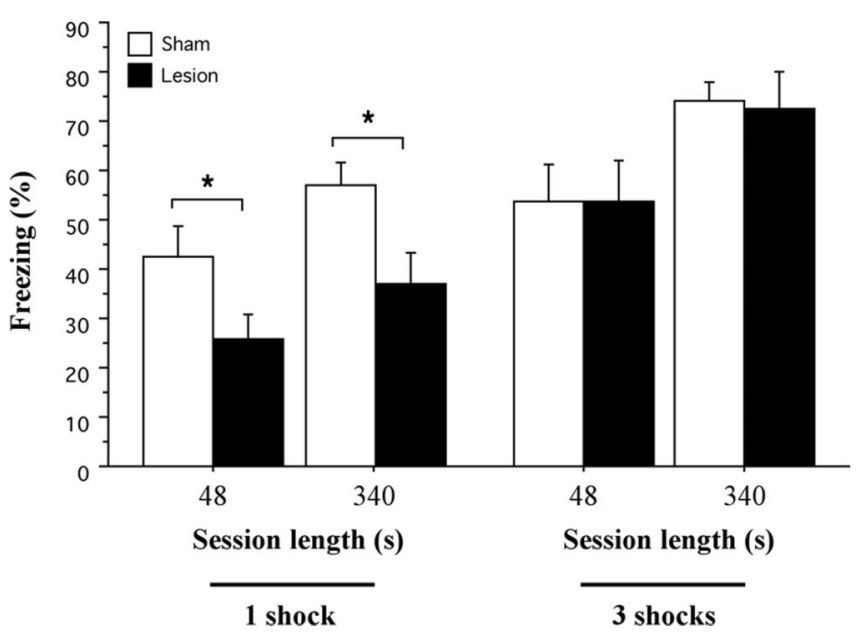

Figure 3. Mean \pm SEM percentage freezing during the context test for sham and DHlesioned animals. Separate groups of animals received one or three shocks during a 48 or $340 \mathrm{~s}$ training session. ${ }^{*} p<0.05$, significant group difference.

$(F<1)$. In contrast, DH-lesioned animals exhibited normal freezing levels after three shocks $(F<1)$. This was true whether the shocks were delivered during a 48 or 340 s session $(F<1)$. This profile was confirmed by a significant trial $\times$ surgery interaction $\left(F_{(1,133)}=3.91 ; p=0.05\right)$. Similar to experiment 1 , the effect of context exposure on conditioning was the same for sham and lesioned animals $(F<1)$.

To determine whether DH lesions altered the timing of the freezing response during the test, we examined the minute-byminute data. Figure $4 A$ illustrates freezing during the context test for animals that received one training trial. Figure $4 B$ shows the
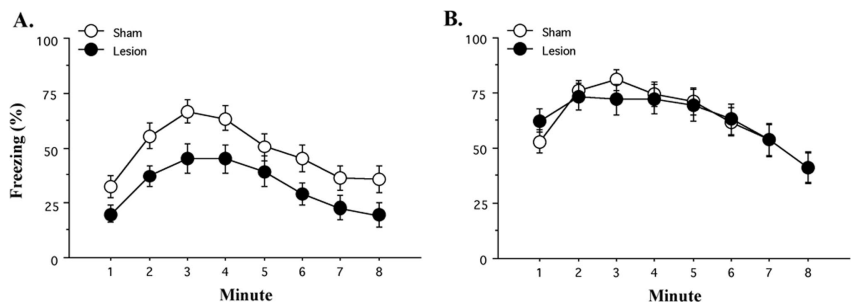

Figure 4. Mean \pm SEM percentage freezing during each minute of the context test for sham and DH-lesioned animals. $\boldsymbol{A}$, Freezing time course for animals receiving a single shock during training. $\boldsymbol{B}$, Freezing time course for animals receiving three shocks during training.
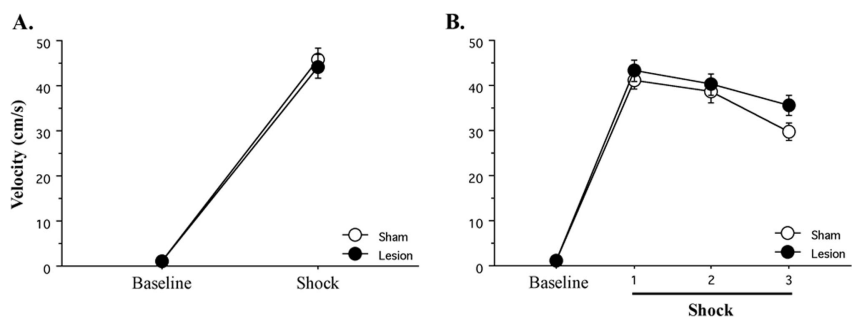

Figure 5. Mean \pm SEM velocity (in centimeters per second) for sham and DH-lesioned animals during the $2 s$ shock and an equivalent baseline period. $\boldsymbol{A}$, Velocity for animals receiving a single shock. $\boldsymbol{B}$, Velocity for animals receiving three shocks.

same data from the three trial groups. The data are collapsed across exposure time because the amount of context exposure (48 or $340 \mathrm{~s}$ ) did not interact with the freezing time course $(F<1)$. Figure $4 A$ shows that the time course of the freezing response was not different between lesions and shams $(F<1)$, although lesioned animals froze at a lower level. Figure $4 B$ illustrates that the freezing time course $(F<1)$ was also the same for $\mathrm{DH}$-lesioned and sham animals receiving multiple trials.

To ensure that DH lesions did not affect shock reactivity, we examined each animal's velocity (activity burst) during shock and an equivalent baseline period. Velocity was measured because we found it to be the most sensitive aspect of shock reactivity (Godsil et al., 1997). Data from the one trial groups is shown in Figure $5 A$. There was a significant increase in velocity during the shock $\left(F_{(1,72)}=584.52 ; p<0.05\right)$ that was equivalent for sham and lesioned animals $(F<1)$. This demonstrates that changes in shock reactivity are not responsible for the decreased context freezing observed in $\mathrm{DH}$-lesioned animals after a single conditioning trial. Figure $5 B$ shows data from the three trial groups. Once again, there was a significant increase in velocity during the $\operatorname{shock}\left(F_{(1,65)}=737.38 ; p<0.05\right)$ that was equivalent in sham and lesioned animals $(F<1)$. Across trials, there was a significant decrease in velocity $\left(F_{(2,130)}=20.42 ; p<0.05\right)$ that was also similar in sham and DH-lesioned rats $\left(F_{(2,130)}=1.11 ; p>0.05\right)$. This reduction is caused by a conditioned analgesic response that develops across trials and reduces the impact of shock (Fanselow, 1984).

These results suggest that the hippocampus is necessary for normal single-trial context conditioning. In contrast, lesioned animals learn to the same level as controls when multiple trials are used. This dissociation cannot be attributed to differences in performance levels. As seen in Figure 3, sham performance was equivalent after one shock delivered at $340 \mathrm{~s}$ or three shocks delivered at $48 \mathrm{~s}(F<1)$, yet lesioned animals were impaired only in the single-trial condition. Therefore, anterograde amnesia for context fear is reliably observed when a single-trial conditioning procedure is used. 
Our laboratory has demonstrated previously that DH lesions produce robust retrograde amnesia for context fear in rats given considerable amounts of training (10-15 trials) (Kim and Fanselow, 1992; Anagnostaras et al., 1999). This is substantially more training than that used in the previous experiment to overcome anterograde amnesia. This suggests that intact animals completely rely on the hippocampus to acquire context fear, even during intensive training. In lesioned animals, these same training procedures engage alternative learning systems. These alternative systems are assumed to be extrahippocampal. However, the lesions made in the current experiments, as in much of the work on context fear, spared the caudal and ventral portions of the hippocampus. Animals may have used these spared portions to acquire context fear. We examined this possibility in our last experiment by training animals with complete hippocampus lesions.

\section{Complete lesions damage the dorsal and ventral hippocampus}

A photomicrograph of a representative complete hippocampus lesion is shown in Figure 6. These excitotoxic lesions caused complete bilateral destruction of the dorsal and ventral hippocampus, including neurons in the dentate gyrus, CA3, and CA1. The data from three animals with substantial cortical shrinkage ( $>35 \%$ reduction in total area) were excluded from all analyses. Five additional animals with minimal remaining hippocampal tissue were also excluded. We did this to ensure that any learning we observed was not mediated by residual hippocampus tissue. Therefore, all of the lesioned rats in this experiment had no detectable hippocampus.

\section{Complete hippocampus lesions produce retrograde but not anterograde amnesia}

Animals were first trained using an intensive conditioning procedure (10 trials) and $1 \mathrm{~d}$ later were given excitotoxic lesions of the hippocampus. As expected, lesioned animals showed severe retrograde amnesia for context fear $\left(F_{(1,32)}=37.2 ; p<0.05\right)$ (Fig. $7)$. These same animals were then retrained using a moderate conditioning procedure (five trials). Similar to the results of our second experiment, lesioned animals showed normal levels of context conditioning $(F<1)$ (Fig. 7). Because the lesions in this experiment were complete, the results suggest that an alternative learning system is able to compensate in the absence of the hippocampus. The fact that the same lesions abolished context fear when made after intense training suggests that this alternative system does not learn when the hippocampus is functional. We should note, however, that some studies have found impaired acquisition of context fear after complete hippocampus lesions (Richmond et al., 1999; Kjelstrup et al., 2002). Procedural differences between these studies and the current experiment may be responsible for this difference. Future studies will be needed to address this issue. Nonetheless, it is abundantly clear from our data that animals with complete hippocampus lesions remain capable of acquiring context fear.

\section{Discussion}

In humans, the ability to form new declarative memories and recall those created in the recent past depends on the integrity of the hippocampus (Squire, 1992). Context fear memories in rodents show a similar dependence on this structure (Kim and Fanselow, 1992). Lesions of the rodent hippocampus produce robust retrograde amnesia for context fear. As in humans, the amnesia is temporally graded and does not extend to context

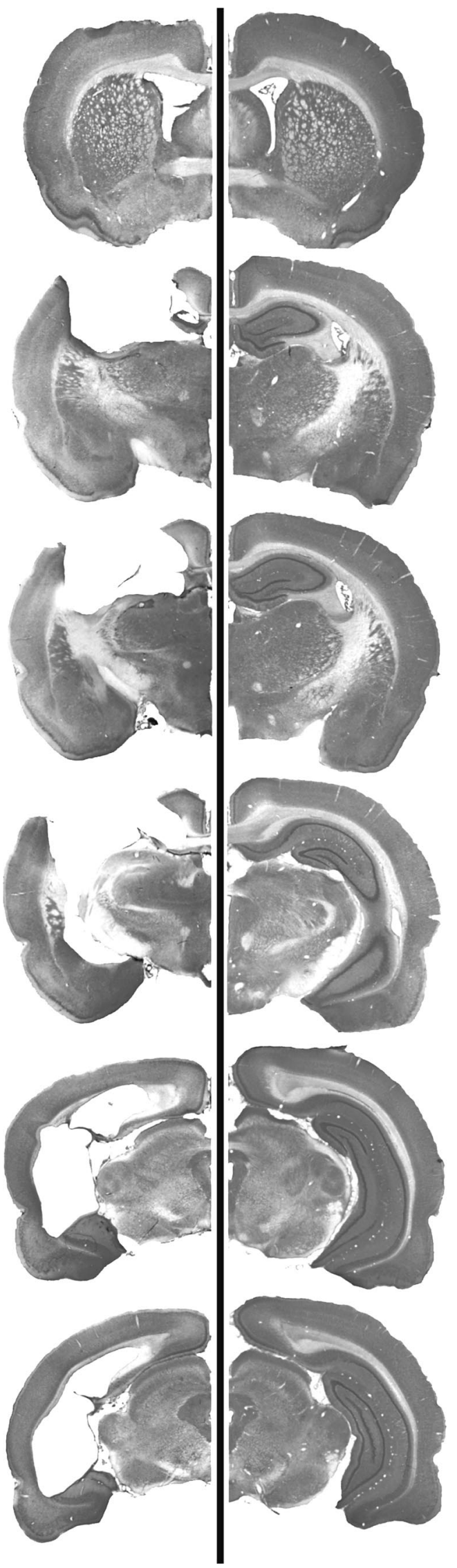

Figure 6. Photomicrographs showing thionin-stained coronal brain sections after excitotoxic lesions of the dorsal and ventral hippocampus (left) or sham surgery (right). From top to bottom, the sections are $-0.30,-1.80,-3.0,-4.0,-4.50$, and $-4.60 \mathrm{~mm}$ posterior to bregma. 


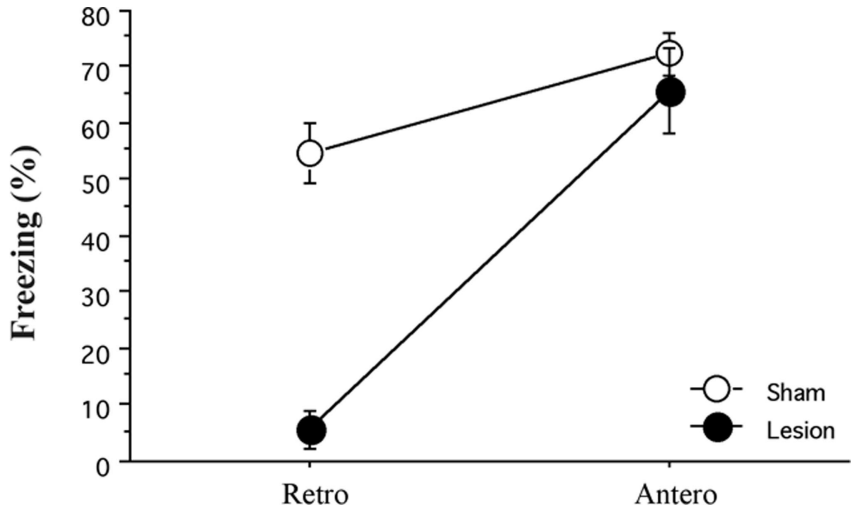

Figure 7. Mean \pm SEM percentage freezing during the context test after posttraining (Retro) or pretraining (Antero) lesions of the hippocampus. Lesions made $1 \mathrm{~d}$ after intense training produced robust retrograde amnesia for context fear. Anterograde amnesia was not observed after moderate retraining. ${ }^{*} p<0.05$, significant group difference.

memories formed in the remote past (Anagnostaras et al., 1999). However, in contrast to the human literature, the ability to form new context fear memories is sometimes spared in lesioned animals (Maren et al., 1997; Cho et al., 1999). The current set of experiments addressed this discrepancy by demonstrating that context fear memories formed during a single learning trial always require the hippocampus. The use of multiple learning trials can overcome this deficit. These results are consistent with studies of spatial memory that show single-trial learning is particularly sensitive to hippocampus disruption (Steele and Morris, 1999; Nakazawa et al., 2003).

The current results fit particularly well with the computational model of O'Reilly and Rudy (2001). This model states that the hippocampus and neocortex work in concert to rapidly acquire detailed information and gradually extract generalities from these acquired experiences. The hippocampus is specialized for rapid learning about stimulus configurations in the environment based on its connectivity and propensity for robust changes in plasticity (McClelland et al., 1995; O'Reilly and Rudy, 2001). In contrast, the neocortex uses a slow learning rate, which allows it to extract information about generalities or statistical regularities that occur over multiple experiences (Racine et al., 1995). If animals with hippocampus damage acquire context information using areas of the neocortex, then this model predicts our results well. As a result of a reduced learning rate, lesioned animals should be most severely impaired after a single learning trial. However, multiple trials should provide the opportunity for the slow learning neocortical system to catch up and eventually reach the same level of performance. This is exactly what we observed. Therefore, we suggest that areas of the neocortex may mediate context fear learning in the absence of the hippocampus. Future studies will be needed to test this idea directly.

Despite learning at a slower rate, the first experiment suggests that animals with hippocampus damage are still able to learn about the context. Increases in the amount of context exposure before shock continued to enhance conditioning in these animals. Previous studies have shown that this enhancement is unique to contextual stimuli; discrete elemental cues tend to produce less conditioning the longer they are presented before an unconditional stimulus (Kamin, 1965; Lubow, 1973; Mackintosh, 1983; Fanselow, 1990). Fanselow (1986) argued that context conditioning requires more time because animals form a configural (i.e., Gestalt) representation of the environment that becomes associated with shock. Consistent with this idea, preexpo- sure to the training context eliminates the gradual increases in context conditioning (Fanselow, 1990). These behavioral results are also consistent with electrophysiological studies that demonstrate that place cell formation in the hippocampus requires several minutes of context exposure (Frank et al., 2004).

Our evidence that animals with hippocampus lesions acquire a representation of the context is at odds with current ideas suggesting that these animals learn about discrete elemental cues (Maren et al., 1997; Frankland et al., 1998; Gerlai, 1998; Fanselow, 2000; Anagnostaras et al., 2001; Matus-Amat et al., 2004). Elemental theories of context learning are based primarily on the fact that lesioned animals have difficulty discriminating between similar environments. For example, Frankland et al. (1998) found that pretraining lesions of the hippocampus impaired the ability of mice to discriminate between a shocked and nonshocked context. Based on this result, they argued that animals with hippocampus lesions must learn about a salient feature present in each environment, which makes it difficult to distinguish between them. In contrast, normal animals were argued to form unique context representations, which allowed them to discriminate easily.

There are two problems with this argument. First, elemental learning theories do not necessarily predict impaired context discrimination. Reduced discrimination requires that animals attend to a common cue present in both contexts. If animals learn about a different element in each environment, then discrimination is trivial. Second, configural learning strategies do not necessarily enhance context discrimination. For example, animals may form configural representations of each environment that contain many of the same individual features. In this case, the overlapping cues will tend to activate the same configural representation (i.e., pattern completion), making discrimination quite difficult. For these reasons, we do not think that reduced context discrimination can be taken as direct evidence for elemental learning.

If rats with hippocampus lesions can form representations of the environment, as our first experiment suggests, then reduced discrimination may result from overlapping context representations. Electrophysiological recording studies are consistent with this idea. Place cells, found in the hippocampus and cortex, fire when an animal is in a particular spatial location (O'Keefe and Nadel, 1978). In the CA1 region of the dorsal hippocampus, these cells have very sharp, high-resolution spatial fields. The fields are also unique and show virtually no overlap, even between similar environments (Sharp, 1999; Frank et al., 2000). In contrast, place cells in the perirhinal, postrhinal, and entorhinal cortex have much larger spatial fields and often show the same firing pattern in different environments (Sharp, 1999; Frank et al., 2000; Fyhn et al., 2004). Therefore, animals with hippocampus lesions may use spatial information from brain regions that have less precise maps of the environment. Large overlap in the place fields formed by these regions would make discrimination between similar environments difficult, as is observed in lesioned animals. Interestingly, this prediction is also made by the computational model of O'Reilly and Rudy (2001). They argue that areas of the neocortex have large overlapping representations that allow them to extract statistical probabilities or generalities. In contrast, the hippocampus has sparse nonoverlapping representations that allow the encoding of unique details of specific events. Therefore, this model also predicts an increase in context generalization as a result of hippocampus damage.

The fact that animals with hippocampus lesions do not learn normally after context preexposure is also taken as evidence for 
elemental learning in lesioned animals. Rudy et al. (2002) showed that preexposure rescues the immediate shock deficit in normal animals but not those with hippocampus lesions. The authors claimed that this occurred because lesioned rats did not have a representation of the context that could be activated after preexposure. However, as we argued in this paper, the observance of a deficit at short intervals is itself evidence that lesioned animals form a representation of the context. Animals using an elemental strategy should learn perfectly well under these conditions (Kamin, 1965; Fanselow, 1990). In addition, the lesioned animals in the experiment of Rudy (2002) did benefit from preexposure, although they remained impaired relative to sham controls. This is analogous to the results of our first experiment; lesioned animals were impaired after a single conditioning trial but continued to benefit from context exposure.

In conclusion, our data suggest that the brain is capable of supporting context fear conditioning by two learning mechanisms, one that depends on the hippocampus and one that does not. Both systems show better learning with more exposure to the context (Fig. 2), and they show similar temporal expression patterns for fear behavior (Fig. 4). However, context learning is clearly more efficient when the hippocampus is intact. A similar profile is observed after lesions of the amygdala. Rats with amygdala damage show impaired fear learning that can be alleviated by overtraining (Maren, 1999; Gale et al., 2004). These rats, however, require significantly more training (75 trials) to acquire normal levels of fear than do rats with hippocampus lesions.

Although context learning is less efficient in animals with hippocampus lesions, conditioning does proceed remarkably well. This contrasts with studies of retrograde amnesia in which posttraining hippocampus lesions produce severe deficits even when a substantial amount of context exposure and many conditioning trials are given (Kim and Fanselow, 1992). This anterograde/retrograde difference suggests that the hippocampus normally prevents context learning in other systems (Wiltgen and Fanselow, 2003; Rudy et al., 2004). Results from other hippocampusdependent tasks support this idea (Solomon et al., 1983; McDonald and White, 1993). Inhibition of alternative learning systems by the hippocampus also explains why anterograde amnesia can be induced by pharmacologic and genetic techniques. These manipulations typically affect plasticity in the hippocampus but not its ability to inhibit or compete with other structures. As a result, hippocampal plasticity and compensation by other structures are impaired. In contrast, if the hippocampus is damaged or inactivated, then compensatory structures are not inhibited and animals are able to learn (Matus-Amat et al., 2004). Studying the interactions between the hippocampus and other learning systems may help us determine why certain brain structures play dominant roles in some learning tasks and not others.

\section{References}

Anagnostaras SG, Maren S, Fanselow MS (1999) Temporally graded retrograde amnesia of contextual fear after hippocampal damage in rats: within-subjects examination. J Neurosci 19:1106-1114.

Anagnostaras SG, Gale GD, Fanselow MS (2001) Hippocampus and contextual fear conditioning: recent controversies and advances. Hippocampus 11:8-17.

Cho YH, Friedman E, Silva AJ (1999) Ibotenate lesions of the hippocampus impair spatial learning but not contextual fear conditioning in mice. Behav Brain Res 98:77-87.

de Hoz L, Moser EI, Morris RG (2005) Spatial learning with unilateral and bilateral hippocampal networks. Eur J Neurosci 22:745-754.

Fanselow MS (1984) Opiate modulation of the active and inactive components of the postshock reaction: parallels between naloxone pretreatment and shock intensity. Behav Neurosci 98:269-277.
Fanselow MS (1986) Associative vs topographical accounts of the immediate shock-freezing deficit in rats: implications for the response selection rules governing species-specific defensive reactions. Learn Motiv $17: 16-39$

Fanselow MS (1990) Factors governing one-trial contextual conditioning. Anim Learn Behav 18:264-270.

Fanselow MS (2000) Contextual fear, gestalt memories, and the hippocampus. Behav Brain Res 110:73-81.

Frank LM, Brown EN, Wilson M (2000) Trajectory encoding in the hippocampus and entorhinal cortex. Neuron 27:169-178.

Frank LM, Stanley GB, Brown EN (2004) Hippocampal plasticity across multiple days of exposure to novel environments. J Neurosci 24:7681-7689.

Frankland PW, Cestari V, Filipkowski R, McDonald RJ, Silva AJ (1998) The dorsal hippocampus is essential for context discrimination but not for contextual conditioning. Behav Neurosci 112:863-874.

Frankland PW, Josselyn SA, Anagnostaras SG, Kogan JH, Takahashi E, Silva AJ (2004) Consolidation of CS and US representations in associative fear conditioning. Hippocampus 14:557-569.

Fyhn M, Molden S, Witter MP, Moser EI, Moser MB (2004) Spatial representation in the entorhinal cortex. Science 305:1258-1264.

Gale GD, Anagnostaras SG, Fanselow MS (2001) Cholinergic modulation of pavlovian fear conditioning: effects of intrahippocampal scopolamine infusion. Hippocampus 11:371-376.

Gale GD, Anagnostaras SG, Godsil BP, Mitchell S, Nozawa T, Sage JR, Wiltgen B, Fanselow MS (2004) Role of the basolateral amygdala in the storage of fear memories across the adult lifetime of rats. J Neurosci 24:3810-3815.

Gerlai R (1998) Contextual learning and cue association in fear conditioning in mice: a strain comparison and a lesion study. Behav Brain Res 95:191-203.

Godsil BP, Spooner JR, Anagnostaras SG, Gale GD, Fanselow MS (1997) Quantification of the unconditional response to footshock in the rat: measurement of the activity burst with the use of computer-based image analysis. Soc Neurosci Abstr 23:1612.

Hannesson DK, Skelton RW (1998) Recovery of spatial performance in the Morris water maze following bilateral transection of the fimbria/fornix in rats. Behav Brain Res 90:35-56.

Kamin LJ (1965) Temporal and intensity characteristics of the conditioned stimulus. In: Classical conditioning (Prokasy WF, ed), pp 118-147. Norwalk, CT: Appleton and Lange.

Kim JJ, Fanselow MS (1992) Modality-specific retrograde amnesia of fear. Science 256:675-677.

Kjelstrup KG, Tuvnes FA, Steffenach HA, Murison R, Moser EI, Moser MB (2002) Reduced fear expression after lesions of the ventral hippocampus. Proc Natl Acad Sci USA 99:10825-10830.

Lubow RE (1973) Latent inhibition. Psychol Bull 79:398-407.

Mackintosh NJ (1983) Conditioning and associative learning. Oxford: Claredon.

Maren S (1999) Neurotoxic basolateral amygdala lesions impair learning and memory but not the performance of conditional fear in rats. J Neurosci 19:8696-8703.

Maren S, Aharonov G, Fanselow MS (1997) Neurotoxic lesions of the dorsal hippocampus and Pavlovian fear conditioning in rats. Behav Brain Res 88:261-274.

Matus-Amat P, Higgins EA, Barrientos RM, Rudy JW (2004) The role of the dorsal hippocampus in the acquisition and retrieval of context memory representations. J Neurosci 24:2431-2439.

McClelland JL, McNaughton BL, O’Reilly RC (1995) Why there are complementary learning systems in the hippocampus and neocortex: insights from the successes and failures of connectionist models of learning and memory. Psychol Rev 102:419-457.

McDonald RJ, White NM (1993) A triple dissociation of memory systems: hippocampus, amygdala, and dorsal striatum. Behav Neurosci 107:3-22.

Nakazawa K, Sun LD, Quirk MC, Rondi-Reig L, Wilson MA, Tonegawa S (2003) Hippocampal CA3 NMDA receptors are crucial for memory acquisition of one-time experience. Neuron 38:305-315.

O'Keefe J, Nadel L (1978) The hippocampus as a cognitive map. London: Oxford UP.

O’Reilly RC, Rudy JW (2001) Conjunctive representations in learning and memory: principles of cortical and hippocampal function. Psychol Rev 108:311-345. 
Paxinos G, Watson C (1998) The rat brain in stereotaxic coordinates, Ed 4. New York: Academic.

Quinn JJ, Oommen SS, Morrison GE, Fanselow MS (2002) Post-training excitotoxic lesions of the dorsal hippocampus attenuate forward trace, backward trace, and delay fear conditioning in a temporally specific manner. Hippocampus 12:495-504.

Racine RJ, Chapman CA, Trepel C, Teskey GC, Milgram NW (1995) Postactivation potentiation in the neocortex. IV. Multiple sessions required for induction of long-term potentiation in the chronic preparation. Brain Res 702:87-93.

Rampon C, Tang YP, Goodhouse J, Shimizu E, Kyin M, Tsien JZ (2000) Enrichment induces structural changes and recovery from nonspatial memory deficits in CA1 NMDAR1-knockout mice. Nat Neurosci 3:238-244.

Richmond MA, Yee BK, Pouzet B, Veenman L, Rawlins JN, Feldon J, Bannerman DM (1999) Dissociating context and space within the hippocampus: effects of complete, dorsal, and ventral excitotoxic hippocampal lesions on conditioned freezing and spatial learning. Behav Neurosci 113:1189-1203.

Rudy JW, Barrientos RM, O’Reilly RC (2002) Hippocampal formation supports conditioning to memory of a context. Behav Neurosci 116:530-538.

Rudy JW, Huff NC, Matus-Amat P (2004) Understanding contextual fear conditioning: insights from a two-process model. Neurosci Biobehav Rev 28:675-685.
Sanders MJ, Fanselow MS (2003) Pre-training prevents context fear conditioning deficits produced by hippocampal NMDA receptor blockade. Neurobiol Learn Mem 80:123-129.

Sharp PE (1999) Complimentary roles for hippocampal versus subicular/ entorhinal place cells in coding place, context, and events. Hippocampus 9:432-443.

Solomon P, Solomon S, van der Schaaf E, Perry H (1983) Altered activity in the hippocampus is more detrimental to classical conditioning than removing the structure. Science 220:329-331.

Squire LR (1992) Memory and the hippocampus: a synthesis from findings with rats, monkeys, and humans. Psychol Rev 99:195-231.

Steele RJ, Morris RG (1999) Delay-dependent impairment of a matching to-place task with chronic and intrahippocampal infusion of the NMDAantagonist D-AP5. Hippocampus 9:118-136.

Wilson MA, McNaughton BL (1993) Dynamics of the hippocampal ensemble code for space. Science 261:1055-1058.

Wiltgen BJ, Fanselow MS (2003) A model of hippocampal-corticalamygdala interactions based on contextual fear conditioning. In: The neurobiology of spatial behaviour (Jeffery KJ, ed), pp 83-103. New York: Oxford UP.

Wiltgen BJ, Sanders MJ, Behne NS, Fanselow MS (2001) Sex differences, context preexposure, and the immediate shock deficit in Pavlovian context conditioning with mice. Behav Neurosci 115:26-32. 